\title{
Surgical Treatment of Traumatic Brain Injuries of Children in Abidjan: Difficulties, Results and Prospects
}

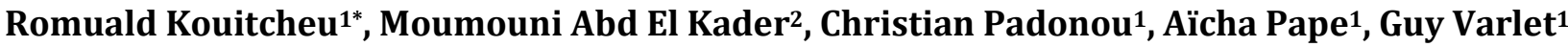 \\ ${ }^{1}$ Neurosurgery Department, CHU Yopougon, Abidjan, Ivory Coast \\ ${ }^{2}$ Departement of Neurosurgery, CHU Sylvanus Olympio, Lomé, Togo \\ Email: *rkouitcheu@yahoo.fr
}

How to cite this paper: Kouitcheu, R., Abd El Kader, M., Padonou, C., Pape, A. and Varlet, G. (2019) Surgical Treatment of Traumatic Brain Injuries of Children in Abidjan: Difficulties, Results and Prospects. Open Journal of Modern Neurosurgery, 9 , 369-378.

https://doi.org/10.4236/ojmn.2019.93034

Received: April 4, 2019

Accepted: July 28, 2019

Published: July 31, 2019

Copyright $\odot 2019$ by author(s) and Scientific Research Publishing Inc. This work is licensed under the Creative Commons Attribution International License (CC BY 4.0).

http://creativecommons.org/licenses/by/4.0/

\begin{abstract}
Introduction: Traumatic brain injury (TBI) in children is a common cause of emergency department admission to our institution. TBI constitutes a real public health problem in developed countries and marked increase in underdeveloped countries. The aim of this study was to evaluate the results of neurosurgical treatment of TBI in children at the neurosurgery department of Yopougon Teaching Hospital, while underlining the difficulties of the adequate management of this affection in Abidjan. Patients and Methods: It was a retrospective, descriptive monocentric study performed in the neurosurgery department, of Yopougon Teaching Hospital-Abidjan (Ivory Coast) from January 2000 to December 2017. We included all patients less than 16 years old admitted to the emergency department and all admitted in neurosurgery department for a TBI with a cerebral tomodensitometry and/or a magnetic resonance imaging having undergone a neurosurgical treatment. Results: During the study period 2825 cases of TBI in children aged less than 16 years old admitted to pediatric emergencies of our institution; among them 1020 (36\%) presented clinical abnormalities and/or imaging. 292 (10.34\%) children were hospitalized in neurosurgery department. 108 (36.9\%) had surgical treatment. The mean age of patients was $7.8 \pm 0.80$ years with a male predominance (64\%). Of the 108 children who had been operated on, 41 had acute extra-dural hematoma evacuation, 22 had a cranio-cerebral wound healing, 36 had a lift from a fracture depressing the skull and 9 had an acute subdural hematoma evacuation with a decompressive flap. The mean delay between diagnosis and surgical care was $104 \pm 67.25$ hours. The postoperative evolution at the last follow-up was favorable in $96(88.8 \%)$ children with sequelae in 12 children (6 language disorders, 2 epileptic seizures and 4 motor defi-
\end{abstract}


cits). The postoperative mortality rate was $11.2 \%$. Conclusion: Ivory Coast Health System does not provide optimal care management of patients with TBI. There is an emerging imperative to develop an insurance system for the management of TBI.

\section{Keywords}

Child, Neurosurgery, Traumatic Brain Injury, Sub-Saharan, Ivory Coast

\section{Introduction}

Traumatic brain injury (TBI) is the result of a direct or indirect mechanical aggression on the skull and underlying brain, immediately presenting disorders of consciousness translating diffuse or localized brain suffering ranging from obnubilation to coma. In developing countries, this condition has become more frequent with the upsurge of road accidents. The possibility of serious secondary complications, sometimes disabling sequelae, socio-economic fallout makes care difficult. TBI represents the first cause of admission to the pediatric emergencies of our institution. TBI constitutes a real public health problem in developed countries and marked increase in underdeveloped countries. In the United States alone, an estimated 475,000 children aged 0 - 14 suffer a traumatic brain injury (TBI) each year. TBI results in more than 7000 deaths, 60,000 hospitalizations, and 600,000 emergency department visits annually among American children [1]. Similarly, TBI affects the pediatric population worldwide. Studies have shown that TBI contributes to more than half of pediatric injuries in Iran, around $20 \%$ of trauma emergency department admissions in India, and around $30 \%$ of pediatric injuries in Korea [2] [3] [4]. Furthermore, TBI affects more than 486 adolescents per 100,000 people per year in Australia and approximately 280 children out of 100,000 people in the United Kingdom [5] [6]. Compared with their adult counterparts, children suffering head injury warrant particular concern given the developmental consequences of early brain damage. In developing countries, the organization of the health system offers victims TBI adequate explorations and a well codified treatment. In Ivory Coast, despite organizational difficulties and problems of financial accessibility to care, care tends to be better and better codified. The aim of this study was to evaluate the results of neurosurgical treatment of TBI in children at the neurosurgery department of Yopougon Teaching Hospital, while underlining the difficulties of the adequate management. This descriptive analysis should serve as a basis for proposing improvement solutions.

\section{Material and Methods}

It was a retrospective, descriptive and cross-sectional study carried out at the neurosurgery department of Yopougon Teaching Hospital-Abidjan (Ivory 
Coast) over a period of 18 years ranging from January 2000 to December 2017. All patients admitted for TBI received a clinical examination assessing their hemodynamic status, their state of consciousness by the Glasgow score, their neurological status and the search for associated lesions. The radiological and biological examinations were requested according to their clinical condition and the financial means of the family. The treatment administered depended on the diagnosis chosen, the availability of the technical platform and the financial means of the family. The surgical indication was retained after consultation with the neurosurgeon and according to the clinical and radiological symptoms.

\section{Inclusion criteria}

Were included all children aged less than 16 years old admitted to pediatric emergencies of our institution then hospitalized in the neurosurgery department for a traumatic brain injury with a cerebral tomodensitometry (CT) and/or a magnetic resonance imaging (MRI) having undergone a neurosurgical treatment.

\section{Exclusion criteria}

Were excluded all children aged less than 16 years old admitted during the study period from traumatic brain injury whose records were incomplete.

\section{Analyzed parameters}

Demographic, clinical, surgical, and post-operative data were collected on an anonymous standardized form. This data was entered and analyzed by the Epi info 7.1 software and then processed with the stata version 12.0 software. A descriptive analysis of the variables was done. Quantitative variables, averages, minima and maxima were also determined. For qualitative variables, the frequencies were calculated. Factors that may influence postoperative mortality: age, nature of lesions, time to surgical management and Glasgow admission score, polytrauma. Comparisons were made using Fisher's test. The significant threshold was $5 \%$.

\section{Results}

\subsection{Epidemiological Criteria}

During the study period 2825 cases of TBI in children aged less than 16 years old admitted to pediatric emergencies of our institution; among them 1020 (36\%) presented clinical abnormalities and/or imaging. 292 (10.34\%) children were hospitalized in neurosurgery department. 108 (3.8\%) had surgical treatment.

\section{Age}

The average age of our patients was $7.8 \pm 0.80$ years old with extremes ( 2 days - 15 years). The most affected age group was (10 - 12) years (Figure 1$)$.

\section{Sex}

Our study population consisted of 69 (64\%) male and 39 (36\%) female. we observed a male predominance with a sex ratio 1.8 (Figure 2).

Mechanism of Trauma

Road accidents were the main causes (78.7\%) followed by falls (Figure 3). 


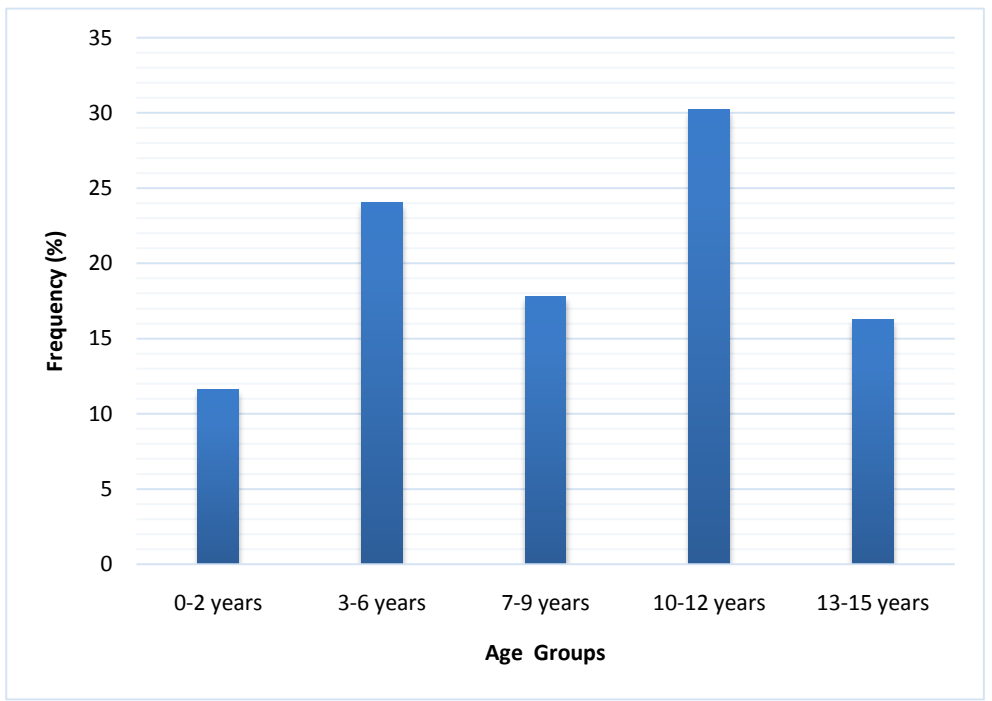

Figure 1. Distribution of children by age groups.

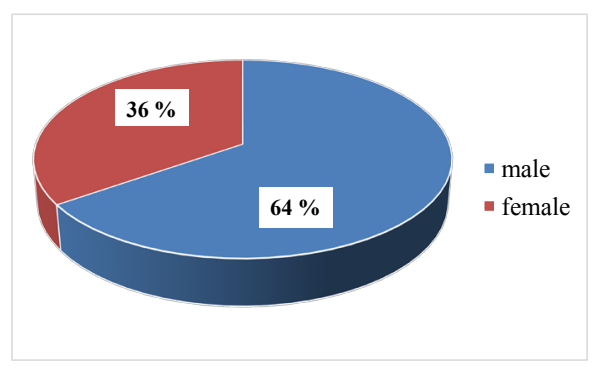

Figure 2. Distribution of children by gender.

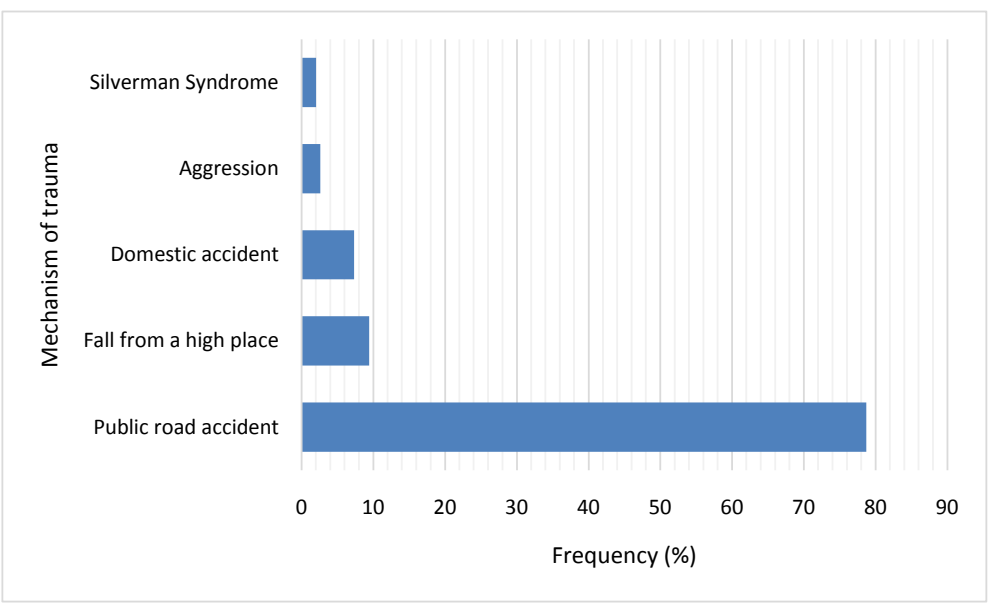

Figure 3. Distribution of children by the mechanism of trauma.

\section{Pre-hospital treatment}

Forty-nine (45\%) had received medical treatment prior to admission. This treatment was indicated in 26 children: 4 had received an analgesic, 8 had venous access, 6 had received anticonvulsant treatment, 2 had oxygen therapy and 6 had received wound suture. 


\section{Transfer to yopougon university hospital}

Transfer to yopougon university hospital was done by vehicle in $45.14 \%$ of cases, motorcycle in $12.71 \%$ of cases, ambulance in $10 \%$ of cases and firefighters in $8 \%$ of cases. The mode of transport was not specified in $24.31 \%$ of the cases.

Clinical criteria

Glasgow Coma Scale (GCS) and Injury Severity (Table 1)

$76(70.4 \%)$ had moderate TBI $(12 \leq \mathrm{GCS} \leq 8)$ and $32(29.6 \%)$ had severe TBI $(\mathrm{GSC} \leq 8)$.

\section{Physical Examination}

Initial loss of consciousness and headache were the main reasons for admission to the emergency room after the injury with a proportion of $87.6 \%$ and $79.2 \%$, respectively (Table 2 ).

\subsection{Paraclinical Criteria}

\section{Anatomoclinical lesions}

All patients performed a brain scan and the operative indication was administered to a patient based on clinical and radiographic symptomatology. The lesions diagnosed were acute extradural hematomas 41 (38\%), acute subdural hematomas $9(0.84 \%)$, cranio-cerebral wounds $22(20.37 \%)$, fracture depressing the skull 36 (33.33\%) (Table 3).

\section{Lésions associated with brain trauma}

The limb trauma, polytrauma and cervical spinal trauma was the most frequent lesion associated found in our patients with a respectively frequency of 9.3\%, $8.6 \%$ and $5.4 \%$ (Table 4 ).

Table 1. Distribution of children by Glasgow Coma Scale (GCS) and injury severity.

\begin{tabular}{cccc}
\hline Injury Severity & GCS & Patients Number & Frequency \\
\hline Moderate & $8-12$ & 76 & $70.4 \%$ \\
Severe & $<8$ & 32 & $29.6 \%$ \\
\hline
\end{tabular}

Table 2. Distribution of patients by clinical signs at admission.

\begin{tabular}{cccc}
\hline & Signs & \multicolumn{2}{c}{ Number/Frequency } \\
\hline & Loss of initial knowledge & $\mathbf{9 4}$ & $\mathbf{( 8 7 . 6 \% )}$ \\
Functional signs & Headache & $\mathbf{8 5}$ & $(\mathbf{7 9 . 2 \% )}$ \\
& Convulsions & 21 & $(19.4 \%)$ \\
Examination of the encephalic & Vomiting & 15 & $(14 \%)$ \\
extremity & Pathological Flows & 18 & $(16.3 \%)$ \\
& Scalps Wounds & 64 & $(59 \%)$ \\
Neurologic examination & Prain Materials Issues & 27 & $(11 \%)$ \\
& Anisocoria & 11 & $(10 \%)$ \\
Somatic examination & Motor Deficit & 5 & $(5 \%)$ \\
\hline
\end{tabular}


Table 3. Distribution of children on Observed anatomoclinical lesions.

\begin{tabular}{ccc}
\hline Lesions & Number & Frequency (\%) \\
\hline Acute Sub dural Hematomas & 9 & 0.84 \\
Cranio-cerebral wounds & 22 & 20.37 \\
Acute extradural Hematomas & 41 & 38 \\
Depressed skull fractures & 36 & 33.33 \\
\hline
\end{tabular}

Table 4. Distribution of children by lesions associated with brain trauma.

\begin{tabular}{ccc}
\hline Associated lesions & Number & Frequency (\%) \\
\hline Limb trauma & 10 & 9.3 \\
Polytrauma & 9 & $8.6 \%$ \\
Cervical Spine trauma & 6 & 5.4 \\
Thoracic Spine Trauma & 1 & 0.77 \\
Rib fractures & 2 & 1.55 \\
Maxillo-facial Trauma & 3 & 2.32 \\
\hline
\end{tabular}

\section{Therapeutic criteria}

Of the 108 children who had been operated on, 41 had extra-dural hematoma evacuation, 22 had a cranio-cerebral wound healing, 36 had a lift from a fracture depressing the skull and 9 had an acute subdural hematoma evacuation with a decompressive flap (Table 5).

The mean time between the accident and the neurosurgical procedure was 104 \pm 67.25 hours. The most common surgical indication was evacuation of extra-dural and a lift from a fracture depressing the skull (Table 5). Among TBI with extra-dural hematoma, there was superior sagittal sinus involvement and transverse sinus involvement. Five patients had a decaying cranio-cerebral wound with significant brain matter; they benefited from craniectomy and dural plasty. The craniectomy was bone lost in 7 patients and 4 other patients underwent remote cranioplasty. The fracture depressing the sk' ull were open in 7 cases and 3 cases were symptomatic closed a fracture depressing the skull.

\subsection{Evolution Criteria}

The most common postoperative clinical manifestations were: headaches (20.4\%), hemiparesis (8.3\%), and language disorders (6.5\%) (Table 6).

The postoperative evolution at the last follow-up was favorable in 96 (88.8\%) children with sequelae in 12 children (6 language disorders, 2 epileptic seizures and 4 motor deficits). The postoperative mortality was $11.2 \%$. Although the majority of deaths occurred in patients operated after 24 hours, there was no statistically significant correlation between mortality and time to surgical management $(p=0.69)$. However, the mortality was correlated with the severity of TBI $(p<0.001)$ and the presence of a neurological deficit $(p=0.01)$ (Table 7$)$. 
Table 5. Distribution of children according to the surgical treatments used.

\begin{tabular}{lll}
\hline Surgical Treatments & Number & Frequency (\%) \\
\hline extra-dural Hematomas evacuation & 41 & 37.96 \\
cranio-cerebral wound healing & 22 & 20.37 \\
lift from a fracture depressing the skull & 36 & 33.33 \\
acute subdural Hematomas evacuation with a decompressive flap. & 9 & 8.33 \\
\hline
\end{tabular}

Table 6. Postoperative clinical features among survivors.

\begin{tabular}{ccc}
\hline & Number & Frequency (\%) \\
\hline Headaches & 22 & 20.4 \\
Hemiparesis & 9 & $\mathbf{8 . 3}$ \\
Language disorders & 7 & 6.5 \\
Convulsions & 4 & 3.7 \\
Olfactory disorders & 2 & 1.8 \\
Hearing Loss & 3 & 2.7 \\
Visual disorders & 5 & 4.6 \\
Neck pain & 2 & 1.8 \\
\hline
\end{tabular}

Table 7. Factors that may impact TBI mortality.

\begin{tabular}{cc}
\hline & $\mathrm{p}$ \\
\hline Age & 0.22 \\
State of Consciousness (Glasgow Coma Score) at admission & $<0.001$ \\
Polytrauma & 0.37 \\
Neurological deficit & 0.01 \\
Intracranial lesions & 0.38 \\
Delay between head trauma and surgical management & 0.069
\end{tabular}

There were 7 (6.49\%) patients who returned for postoperative control at one month, and 4 patients (3.70\%) returned for control at 6 months.

\section{Discussion}

The practice of neurosurgery in Ivory Coast still faces a number of difficulties, namely the accessibility of populations to radiological investigations; neurosurgeon insufficiency, the ratio of neurosurgeon in Ivory Coast was $1 / 2,000,000$ inhabitants whereas this ratio was $1 / 200,000$ inhabitants in the developed countries [7], and the insufficiency of unit care: 0.166 units/1,000,000 inhabitants in Ivory Coast and other sub-Saharan countries such as Uganda [8]. This ratio was lower than observed in South Africa (8.9 units/100,000 inhabitants), Sri Lanka (1.6 units/100,000 inhabitants) and the United States of America (20 units/100,000inhabitants) [9]. At the same time, the incidence of TBIs ranged from 150 to 170 cases per 100,000 population, while the global incidence was 106 cases per 100,000 population [10].

As we have said, this was a retrospective study in a hospital setting which constitutes a recruitment bias. Nevertheless, we observed that traffic accidents were the main etiologies (87\%) and that children in the age group (10 - 12 years), males were the most exposed as confirmed by several authors [11] [12] [13] [14]. 
The frequency of surgical treatment was $3.8 \%$ and this rate was lower than the $11.76 \%$ of surgery in children reported by Fatigba who works under the same conditions as us in Parakou [15]. This low rate of TBI surgery was probably due to the low rate of patients who could perform the brain scan [16] thus reducing the rate of lesional diagnosis and thus the surgical indications. Children, with a more elastic and thinner skull, absorb kinetic energy, causing more frequent lo$\mathrm{cal}$ lesions. There is thus no direct correlation between the presence of a radiological lesion and the state of consciousness of TBIs.

The management system requiring prepayment of consumables and patient care, this lengthens the waiting time, which was 104 hours on average when it should be less than 24 hours [17]. A time often needed by the family to raise funds to honor care benefits. As a reminder, knowing that in Ivory Coast, the SMIG is 61 euros and that the average cost at the initial phase of the handling of mildTBIs in Ivory Coast is estimated at 188.21 euros and 522.12 euros for severe TBI, a number of patients admitted to severe TBI could not be explored in time. All our operated patients could be explored by the brain scanner. Extradural hematoma and embarrassment were the most common lesions in our series. The evacuation of extradural hematomas and dural plasty were the surgical indications that we had most often used in our series. The low rate of decompressive flap is due to the fact that the lesion diagnosis is very often late because of cost of performing the brain scanner and the absence of a monitor for measuring intracranial pressure. These interventions were performed with the basic neurosurgery instruments we have.

In our series, we have a postoperative mortality of $11.2 \%$, the majority of which had a Glasgow score of $\leq 8$. The delay in treatment of these severe TBI and the severity of the lesions may explain this mortality. The majority of patients were lost to follow-up. The main reasons were the balance of hospital costs not fully paid by the patients, and the distance to go to the neurosurgery consultations.

To optimize the management of TBI in Ivory Coast, it is necessary to establish a protocol for pre-hospital care, by developing the emergency medical assistance service, as well as a road safety fund. ensuring the management of traffic accidents, to reduce the time to explore and support TBIs.

\section{Conclusion}

TBI in children is a health problem in our country. Currently, the organization of care generates a waiting time for excessive care, which is detrimental to the quality of management and prognosis of TBI. It would be necessary to set up a road guarantee fund to optimize the accessibility of neurosurgical care and ensure better follow-up of patients.

\section{Conflicts of Interest}

The authors declare no conflicts of interest regarding the publication of this paper. 


\section{References}

[1] Dewan, M.C., Mummareddy, N., Wellons III, J.C. and Bonfield, C.M. (2016) Epidemiology of Global Pediatric Traumatic Brain Injury: Qualitative Review. World Neurosurgery, 91, 497-509. https://doi.org/10.1016/j.wneu.2016.03.045

[2] Kim, H.B., Kim, D.K., Kwak, Y.H., Shin, S.D., Song, K.J., Lee, S.C., et al. (2012) Epidemiology of Traumatic Head Injury in Korean Children. Journal of Korean Medical Science, 27, 437-442. https://doi.org/10.3346/jkms.2012.27.4.437

[3] Tabish, A., Lone, N.A., Afzal, W.M. and Salam, A. (2006) The Incidence and Severity of Injury in Children Hospitalised for Traumatic Brain Injury in Kashmir. Injury, 37, 410-415. https://doi.org/10.1016/j.injury.2006.01.039

[4] Chabok, S.Y., Ramezani, S., Kouchakinejad, L. and Saneei, Z. (2012) Epidemiology of Pediatric Head Trauma in Guilan. Archives of Trauma Research, 1, 19-22. https://doi.org/10.5812/atr.5381

[5] Mitra, B., Cameron, P.A., Butt, W. and Rosenfeld, J.V. (2006) Children or Young Adults? A Population-Based Study on Adolescent Head Injury. ANZ Journal of Surgery, 76, 343-350. https://doi.org/10.1111/j.1445-2197.2006.03723.x

[6] Hawley, C.A., Ward, A.B., Long, J., Owen, D.W. and Magnay, A.R. (2003) Prevalence of Traumatic Brain Injury amongst Children Admitted to Hospital in One Health District: A Population-Based Study. Injury, 34, 256-260.

https://doi.org/10.1016/S0020-1383(02)00193-6

[7] Dechambenoit, G. (2016) Access to Health Care in Sub-Saharan Africa. Surgical Neurology International, 7, 108. https://doi.org/10.4103/2152-7806.196631

[8] Kwizera, A., Dünser, M. and Nakibuuka, J. (2012) National Intensive Care Unit Bed Capacity and ICU Patient Characteristics in a Low Income Country. BMC Research Notes, 5, 475. https://doi.org/10.1186/1756-0500-5-475

[9] Adhikari, N.K., Fowler, R.A., Bhagwanjee, S. and Rubenfeld, G.D. (2010) Critical Care and the Global Burden of Critical Illness in Adults. The Lancet, 376, 1339-1346. https://doi.org/10.1016/S0140-6736(10)60446-1

[10] Odero, W., Garner, P. and Zwi, A. (1997) Road Traffic Injuries in Developing Countries: A Comprehensive Review of Epidemiological Studies. Tropical Medicine \& International Health, 2, 445-460. https://doi.org/10.1111/j.1365-3156.1997.tb00167.x

[11] Ghajar, J. (2000) Traumatic Brain Injury. The Lancet, 356, 923-929. https://doi.org/10.1016/S0140-6736(00)02689-1

[12] Hyder, A.A., Wunderlich, C.A., Puvanachandra, P., Gururaj, G. and Kobusingye, O.C. (2007) The Impact of Traumatic Brain Injuries: A Global Perspective. NeuroRehabilitation, 22, 341-353.

[13] Fatigba, H.O., Savi de Tove, M.K., Tchaou, B.A., Mensah, E., Allode, A.S. and Padonou, J. (2013) Surgical Management of Head Trauma: Problems, Results, and Perspectives at the Departmental Teaching Hospital of Borgou, Benin. World Neurosurgery, 80, 246-250. https://doi.org/10.1016/j.wneu.2011.09.016

[14] Beavogui, K., Koivogui, A., Souare, I., Camara, D., Cherif, M., Dramou, B., et al. (2012) Profile of Cranio-Cerebral Trauma and Spinal Cord Trauma Related Road Accidents in Guinea. Neurochirurgie, 58, 287-292. https://doi.org/10.1016/j.neuchi.2012.05.006

[15] Hode, L., Sogbo, D.O., Hounnou, M.G., Houessou, G.F., Voyeme, A.A. and Chobli, M. (2016) Prise en charge des traumatismes cranio-encephaliques chez les enfants à Cotonou. African Journal of Neurological Sciences, 35, 55-65. 
[16] Hode, L., Madougou, S., Fatigba, H.O., Hounnou, P., Ebassa, K., Moevi, A.A.H., et al. (2017) The Direct Cost of Treatment of Traumatic Brain Injury in a Sub-Saharan African Country (Benin). World Neurosurgery, 99, 210-213. https://doi.org/10.1016/j.wneu.2016.11.083

[17] Jennett, B. and Bond, M. (1975) Assessment of Outcome after Severe Brain Damage: A Practical Scale. The Lancet, 305, 480-484.

https://doi.org/10.1016/S0140-6736(75)92830-5 